Original Research Paper

\title{
The Role of Blended Learning on Student Performance in Biotechnology Course
}

\author{
Zahra Sarabadani and Aydin Berenjian \\ School of Engineering, Faculty of Science and Engineering, The University of Waikato, Hamilton, New Zealand
}

\author{
Article history \\ Received: 04-08-2017 \\ Revised: $16-08-2017$ \\ Accepted: 22-08-2017 \\ Corresponding Author: \\ Aydin Berenjian \\ School of Engineering, Faculty \\ of Science and Engineering, \\ The University of Waikato, \\ Hamilton, New Zealand \\ Tel: +64 78585119 \\ Email: aydin.berenjian@waikato.ac.nz
}

\begin{abstract}
The present work aims for evaluating the role of blended learning on student engagement and performance in bioreactor design component of the biotechnology course. Interactive online module covering the main fundamental aspects of the subject was developed and made available to students prior to the class. Students who accessed the online module found to be more active in classroom response participations $(p<0.05)$ and received higher marks in the examination $(p<0.05)$. These data highlight the key role of blended learning in improving the student learning desire and academic performance.
\end{abstract}

Keywords: Biotechnology, Blended Learning, Class Participation, Active Learning, Pedagogical Thinking

\section{Introduction}

Teacher centred lectures are the main method in delivering the course materials in engineering education. Yet, this practice has significant shortcomings as students rely on lecturers to decide what, when and how to learn which limits their engagement and learning outcomes (Zakaria and Iksan, 2007). Therefore, there is a substantial need for innovative pedagogical thinking to address the current challenges associated with traditional classroom teaching. Student-centred learning approaches that shift the instruction focus from teacher to student can be seen as a paradigmatic shift in engineering education (Rust, 2002). Blended learning is a type of Student-centred learning method that combines the traditional class room methods with online technology mediated learning environment (Garrison and Kanuka, 2004).

In this approach fundamental content of the course will be provided online for the students to be learned prior to their classroom attendance (Valtonen et al., 2012). During the classroom session, the majority of the lecture time will be devoted to active learning practices and discussions (Gülbahar, 2008). Blended learning by benefiting from both e-learning and face-to-face teaching environment provides a platform that facilitates the acquisition of graduate attributes that may not be achievable otherwise (Garrison and Kanuka, 2004).
Blended learning provides learners with greater control over the reading materials and the pace of learning with self-assessment opportunities (Tuapawa, 2017). While it seems that this method has a positive influence on students learning, there is a lack of research on how this approach would benefit Chemical Engineering students within a biotechnology course. Therefore, the main aim of the present study was to evaluate the role of blended learning on enhancing the students' engagement and learning outcomes.

\section{Methodology}

Bioreactor selection is covered in a six-class lectures in the biotechnology course at the University of Waikato. These sessions cover a range of design and concepts of solid and liquid state bioreactors and their applications. For many years, these material were delivered with the help of traditional face to face lecture system. In this study, bioreactors sessions were redesigned and changed to blended-learning model.

The course key components were embedded into interactive module along with self-assessment and pre-test segments. Students were required to complete all the online tasks prior to classroom attendance. Both pre-test and post-test protocols were used to analyse and evaluate the results. Learning objectives 
for modules were mainly based on content quality and the use of technology as tabulated in Table 1.

The majority of the class time was focused on active learning exercise, real-world case based discussions and brief lectures. A final exam covering the bioreactors content was in multiple choice question format in order to minimize the marking errors. The correlation between the online modules and student performance was recorded for each individual student. Analysis Of Variance (ANOVA) with post-hoc mean comparison with Tukey test was used to evaluate participation (\%) and performance (\%) of the students. Statistical significance level were set at $p<0.05$.

\section{Results and Discussion}

Based on the results, students who accessed all the online modules as compared to the ones who did not used all the components, scored higher in the examination and were found to be more active in response system questions $(p<0.05)$. For the components that were not specifically covered by the online module there were no significant difference between the students exam marks $(p>0.05)$. However, the lowest exam marks were for the students who never used any of the online materials.

In general, students who used the online materials scored significantly higher in both response system and examination performance as compared to the ones who never accessed any online modules $(p<0.05)$. The survey on the learning objectives from Table 1 showed that the majority of students who used online materials strongly agreed that online module was helpful to integrate theory and experiment and was successful in assessing their learning performance (Table 2).

Students agreed that online module was so useful on enhancing their engagement with the course content. Students also agreed that online content was motivating enough and was helpful in gaining industrial insight into the bioreactor design process. However, students disagreed that the online module by itself could satisfy the need for lecturer guidance.

Blended-learning techniques has found application in several engineering disciplines to foster students learning (Kist et al., 2013; Egan et al., 2017). However, in depth understanding on how this methodology would affect different engineering courses in terms of student engagement and learning outcomes is of significant demand. Our results demonstrate the positive role of blended learning and computer mediated teaching environment on student engagement and academic performance. Online module found to be supportive on advancing the understanding of fundamentals, integrating theory and experiment and gaining industrial insight into the process.

However, students found blended approach complementary to the traditional lectures not as a replacement. This observation can be justified by the fact that this learning method reinforces the fundamentals so that the students could further connect and understand complex industrial challenges and ideas. However, we need to acknowledge that there are various factors associated with blended learning that can negatively affect the student learning outcomes. Lecturer needs to be aware that the online mediated instructions may not be appropriate to all the lecture materials. Blended learning approach requires the computer access and online technological support for the student. Also, learner interaction and satisfaction could be another challenge associated with online learning environment (McLaughlin et al., 2015). However, despite the mentioned limitations, from the results of the present study application of blended learning method in parts of the biotechnology course found to be a promising learning method to enhance the students learning desire and improving their learning outcomes.

Table 1. Learning Objectives for bioreactor design component Questions for analysis

- Was online module helpful to integrate theory and experiment?

- Was online module useful in better engagement with the course content?

- Was online module helpful by itself without the lecturer help?

- Was the online module content motivating enough?

- Was the online module useful in gaining industrial insight into the bioreactor design process?

- Was the online module useful in assessing your learning performance?

Table 2. Students performance overview

\begin{tabular}{lll}
\hline & Used all online modules (\%) & Never used online modules (\%) \\
\hline Participation & 92 & 65 \\
Automated response system performance & 88 & 63 \\
Exam performance & 81 & 78 \\
\hline
\end{tabular}




\section{Conclusion}

Blended learning is becoming a predominant classroom component in many universities to actively engage students in the learning process. Based on the results of the current study, online bioreactor design content of the biotechnology course significantly enhanced the student in-class engagement and academic performance. As a result, this study points out the key role of integrating online modules with face to face classroom settings in improving students active learning. The emerging achievements of the present study in creating online Biotechnology course needs further research.

\section{Acknowledgement}

The work was supported by the University of Waikato.

\section{Author's Contributions}

Zahra Sarabadani: Analysed the data. Aydin Berenjian: Designed and developed the study.

\section{Ethics}

The article is original and has not been formally published in any other peer-reviewed journal and does not infringe any existing copyright and any other third party rights.

\section{References}

Egan, S., F. Waugh, R. Giles and W. Bowles, 2017. Authentic assessment: Partners in developing a webbased guide. Social Work Education, 36: 731-744.

Garrison, D.R. and H. Kanuka, 2004. Blended learning: Uncovering its transformative potential in higher education. Internet Higher Education, 7: 95-105.
Gülbahar, Y., 2008. ICT usage in higher education: A case study on preservice teachers and instructors. Turkish Online J. Educational Technol., 7: 32-37.

Kist, A.A., A. Maiti, A.D. Maxwell and L. Orwin, 2013. Performance evaluation of network architectures for collaborative real-time learning systems. Proceedings of the IEEE International Conference on Teaching, Assessment and Learning for Engineering, (TALE' 13).

McLaughlin, J.E., N. Gharkholonarehe, J. Khanova, Z.M. Deyo and J.E. Rodgers, 2015. Instructional design and assessment the impact of blended learning on student performance in a cardiovascular pharmacotherapy course. Am. J. Pharmaceutical Educ.

Rust, C., 2002. The impact of assessment on student learning: How can the research literature practically help to inform the development of departmental assessment strategies and learner-centred assessment practices? Active Learning Higher Educ., 3: 145-158.

Tuapawa, K., 2017. Educational online technologies in blended tertiary environments: Experts' perspectives. Int. J. Inform. Commun. Technol. Educ., 13: 1-14.

Valtonen, T., K. Mäkitalo-Siegl, S. Kontkanen, S. Pöntinen and H. Vartiainen, 2012. Facing challenges with new teachers' use of ICT in teaching and learning. Bull. Technical Committee Learning Technol., 14: 46-49.

Zakaria, E. and Z. Iksan, 2007. Promoting cooperative learning in science and mathematics education: A Malaysian perspective. Eurasia J. Math. Sci. Technol. Educ., 3: 35-39. 